\title{
Factors influencing Saudi medical students and interns' choice of future specialty: a self-administered questionnaire
}

This article was published in the following Dove Press journal:

Advances in Medical Education and Practice

24 October 2014

Number of times this article has been viewed

\section{Mohammed Alshahrani \\ Bander Dhafery \\ Mohammed Al Mulhim \\ Faisal Alkhadra \\ Doaa Al Bagshi \\ Noor Bukhamsin \\ King Fahad Hospital of the University, Dammam University, Al Khobar, Kingdom of Saudi Arabia}

Background: This study explores the most influential factors affecting Saudi medical students and interns' choice of specialty at the University of Dammam, Kingdom of Saudi Arabia.

Methods: A self-administered questionnaire was distributed during the period from June 1 to June 14, 2013. Chi-square test and logistic regression were used to test the association between participants' choices and the motivational factors that led to their choice of specialty.

Results: One-hundred sixty-eight (44.7\%) participants chose lifestyle as their most influential factor for the choice of their specialty. Significantly more medical interns considered lifestyle as an important factor compared to medical students $(P=0.020)$. Internal medicine was the preferred specialty for 56 participants $(14.77 \%)$ followed by family medicine for 35 participants $(9.2 \%)$. Thirty-four participants (8.97\%) chose general surgery, and 27 participants $(7.1 \%)$ chose both pediatrics and emergency medicine. Sex influences indicated that men preferred pediatrics and emergency medicine ( $P=0.033$ and $P=0.0006$, respectively), while women preferred family medicine practice $(P=0.034)$.

Conclusion: Saudi medical students and interns at the University of Dammam were influenced mostly by lifestyle when they considered their future specialty. Internal medicine, family medicine, general surgery, pediatrics, and emergency medicine were the preferred specialties.

Keywords: medical students, interns, specialty preference, motivational factors, lifestyle

\section{Introduction}

The choice of a future career in medical practice can be a daunting experience for medical students and interns, as there are many factors to consider. To date, most studies on this topic are from Western countries. ${ }^{1}$ In 1967, the first medical school in Saudi Arabia was established at King Saud University. By 2011, there were 21 medical colleges in the Kingdom of Saudi Arabia. ${ }^{2}$ Medical students spend 6 years of study and 1 year in an internship before graduation. In the fourth year of medical school, students begin their clinical rotations, where they are exposed to patients and specialties for 1-6 weeks in each rotation depending on the specialty they are assigned. After graduation, each student chooses a specialty for a further residency training program to become a full specialist in that field.

In February 2012, the Ministry of Health, Kingdom of Saudi Arabia, released a Statistics Book on their official website, which indicates that the total number of physicians (including physicians at private clinics) in the Kingdom is 69,226 and only $22.4 \%$ of them are Saudi. ${ }^{3}$ Table 1 shows the distribution of specialized Saudi physicians across the Kingdom of Saudi Arabia, which clearly indicates the shortage of
Correspondence: Mohammed Alshahrani Emergency and Critical Care Consultant, King Fahad Hospital of the University, Dammam University, PO Box 40236, Al Khobar 31952, Kingdom of Saudi Arabia Tel +966556966663

Email msshahrani@ud.edu.sa 
Table I Percentage of Saudi physicians per specialty working at Saudi Ministry of Health hospitals ${ }^{3}$

\begin{tabular}{ll}
\hline Percentage of Saudi physicians & Specialty \\
\hline 33.0 & General practitioner \\
43.1 & Dentistry \\
19.1 & Internal medicine \\
21.4 & General surgery \\
12.9 & Orthopedics \\
17.2 & Urology \\
12.4 & Cardiothoracic surgery \\
17.7 & Neurosurgery \\
13.9 & Plastic \\
22.6 & ENT \\
25.6 & Ophthalmology \\
14.9 & Obstetrics and gynecology \\
17.1 & Cardiology \\
8.0 & Chest disease \\
38.6 & Skin and venereology \\
32.2 & Neurology \\
19.4 & Public health \\
25.0 & Tropical medicine \\
21.9 & Radiology \\
9.4 & Laboratory \\
4.6 & Anesthesia \\
46.7 & Physical medicine \\
22.8 & Pediatric \\
21.6 & Psychiatry \\
26.7 & Forensic medicine \\
22.0 & Family medicine \\
11.4 & Emergency medicine \\
13.9 & Intensive care \\
7.3 & Nephrology \\
15.0 & Pediatric surgery \\
24.5 & Blood disease \\
23.1 & Gastroenterology \\
37.3 & Endocrinology \\
19.2 & Oncology \\
8.6 & Vascular disease \\
34.2 & Others \\
23.0 & Total \\
\hline &
\end{tabular}

Note: ENT, ear, nose, and throat.

specialized Saudi physicians in almost all medical specialties. According to the report "Specialized Saudi medical doctors are still in high demand in most Saudi secondary and tertiary hospitals". ${ }^{3}$ In the same report, the physician-to-patient ratio in the Saudi community was calculated to be 2.4 physicians for every 1,000 people.

Saudi Arabia has 13 regions. There are differences in population, number of medical colleges, and requirement of health facilities in each region of Saudi Arabia. In a recent study performed in the southern region at King Khalid University College of Medicine, Mehmood et $\mathrm{al}^{4}$ found that surgery, internal medicine, pediatrics, orthopedics, and ophthalmology were the preferred specialty choices for medical students. The eastern region is the largest region in Saudi Arabia by surface area and population (4 million people). It has two medical colleges that admit 400-500 students every year from inside the region. The eastern region has different characteristics, in that there are more industrial cities and oil companies, which create more occupational health hazards, and more numbers of younger people live there. All of this might result in different medical needs and specialists compared with other regions.

To the best of our knowledge, no study has explored the career choices of medical students and interns in this region of the Kingdom of Saudi Arabia before. Therefore, we conducted the present study to look for factors that influence career choice. With this objective in mind, we devised a questionnaire for medical students and interns to assess their thinking about their choice of specialization and the factors influencing their decision. Our analysis included an examination of different associations among demographic variables, motivational factors, and specialty selection.

\section{Methods}

After obtaining approval from the Institutional Review Board of the King Fahd Hospital of the University, Al Khobar, Kingdom of Saudi Arabia, we conducted a cross-sectional survey of a study cohort of medical students and interns in their fourth, fifth, and sixth clinical years at the University of Dammam, Kingdom of Saudi Arabia. We sent the questionnaire to 651 voluntary participants during the first 2 weeks of June 2013. A structured, self-administered questionnaire consisting of seven close-ended questions in English was distributed to all potential participants after their final year exams. The first four questions were about demographics of the students, like their age, sex, level of training (fourth, fifth, sixth year, or medical intern) and their grade point average (GPA). The remaining questions were about factors affecting their specialty choice, which included lifestyle (controllable vs uncontrollable) as explained during the distribution of the questionnaire.

The questionnaire also asked students about their subspecialty choice. When students select a subject as their specialty, they have to study some other subjects related to that specialty. An example of this is cardiology, which is a subspecialty of internal medicine (Table 2). When choosing a medical specialty (Table 3 ), students also have to consider where they want to do their residency (Table 4). A student at the time of specialty selection might think of the subspecialty subjects as being more important than the major specialty itself. 
Table 2 Motivational factors with academic level influence

\begin{tabular}{|c|c|c|c|c|}
\hline Motivational factor & $\begin{array}{l}\text { Medical } \\
\text { students } \\
(n=3 \mid 0)\end{array}$ & $\begin{array}{l}\text { Medical } \\
\text { interns } \\
(n=66)\end{array}$ & $\begin{array}{l}\text { Total } \\
\text { number }\end{array}$ & $P$-value \\
\hline Controllable lifestyle & 130 & 38 & 168 & 0.020 \\
\hline Prestige & 7 & 0 & 7 & 0.61 \\
\hline Subspecialty choice & 40 & 9 & 49 & 0.87 \\
\hline $\begin{array}{l}\text { Residency training } \\
\text { intensity }\end{array}$ & 14 & 2 & 16 & 0.058 \\
\hline $\begin{array}{l}\text { Clinical rotation } \\
\text { experience }\end{array}$ & 40 & 3 & 43 & 0.052 \\
\hline Income & 15 & 3 & 18 & 0.90 \\
\hline Working hours & 6 & 0 & 6 & 0.25 \\
\hline Personal interest & 7 & 0 & 7 & 0.218 \\
\hline Role model effect & 7 & 2 & 9 & 0.70 \\
\hline Nature of patient care & I & 0 & & 0.39 \\
\hline Training place & I & 0 & I & 0.39 \\
\hline Family influence & 15 & 2 & 17 & 0.52 \\
\hline Future job security & 10 & 4 & 14 & 0.27 \\
\hline
\end{tabular}

Each participant was asked to choose the three most important factors that influenced their specialty decision. Participants were allowed to add a specialty if it was not mentioned in the questionnaire. The data were entered into a database and analyzed using SPSS software (version 17; SPSS Inc., Chicago, IL, USA). The chi-square test was used to assess the association between the outcome variable, specialty choice, and motivational factors, future training place and the sex, and sociodemographic and academic characteristics of the participants

Table 3 Specialty choices and sex influence

\begin{tabular}{|c|c|c|c|c|}
\hline Specialty & $\begin{array}{l}\text { Male } \\
(n=126)\end{array}$ & $\begin{array}{l}\text { Female } \\
(n=253)\end{array}$ & $\begin{array}{l}\text { Total } \\
(n=379)\end{array}$ & $P$-value \\
\hline Internal medicine & 18 & 38 & 56 & 0.84 \\
\hline General surgery & 13 & 21 & 34 & 0.51 \\
\hline Pediatrics & 14 & 13 & 27 & 0.033 \\
\hline Obstetrics and gynecology & 3 & 18 & 21 & 0.058 \\
\hline Emergency medicine & 17 & 10 & 27 & 0.0006 \\
\hline Family medicine & 6 & 29 & 35 & 0.034 \\
\hline Radiology & 3 & 11 & 14 & 0.339 \\
\hline Neurology & 4 & 9 & 13 & 0.84 \\
\hline Dermatology & 5 & 8 & 13 & 0.68 \\
\hline Neurosurgery & 4 & 9 & 13 & 0.84 \\
\hline Ophthalmology & 4 & 13 & 17 & 0.38 \\
\hline ENT & 5 & 7 & 12 & 0.52 \\
\hline Plastic surgery & I & 7 & 8 & 0.208 \\
\hline Cardiac surgery & I & 6 & 7 & 0.28 \\
\hline Thoracic surgery & 5 & 3 & 8 & 0.070 \\
\hline Vascular surgery & 0 & 1 & I & 0.48 \\
\hline Anesthesia & I & I & 2 & 0.61 \\
\hline Pathology & 2 & 5 & 7 & 0.79 \\
\hline Others & 4 & 4 & 8 & 0.309 \\
\hline Undecided & 9 & 32 & 41 & 0.104 \\
\hline
\end{tabular}

Note: The bold values indicate specialties that are statistically significant between male and female sex when choosing specialty.

Abbreviation: ENT, ear, nose, and throat.
Table 4 Choice of future training place

\begin{tabular}{|c|c|c|c|c|}
\hline Training place & $\begin{array}{l}\text { Male } \\
(n=125)\end{array}$ & $\begin{array}{l}\text { Female } \\
(n=\mid 46)\end{array}$ & $\begin{array}{l}\text { Total number } \\
(n=27 I)\end{array}$ & $P$-value \\
\hline $\begin{array}{l}\text { Local (Saudi health } \\
\text { specialties programs) }\end{array}$ & 78 & 140 & 218 & 0.22 \\
\hline $\begin{array}{l}\text { International (USA, } \\
\text { Canada, others) }\end{array}$ & 47 & 106 & 153 & 0.39 \\
\hline
\end{tabular}

(medical students vs interns). Multivariate regression analysis was conducted; the dependent variable was the decision on the most influential factor in choosing a specialty and the independent variables were age, education level (medical student or intern), sex, and GPA. A value of $P \leq 0.05$ was considered significant with a $95 \%$ confidence interval.

\section{Results}

Three hundred seventy-nine (58\%) participants responded to our questionnaire. The demographic data of the participants showed that the male and female distribution of responses was $126(33.25 \%)$ and $253(66.75 \%)$, respectively. The average age of the participants was between 18 and 24 years $(n=318$; $83.91 \%)$. The distribution of participants based on their level of education showed that 82 students $(21.64 \%)$ were in their fourth year, $90(23.75 \%)$ in their fifth year, and $140(36.94 \%)$ in their sixth year, and $67(17.68 \%)$ were medical interns.

The average GPA of all participants was 5, with 165 (44\%) participants having a GPA above 4.1, 96 (25.6\%) between 3.6 and 4.09, 70 (18.67\%) between 3.1 and 3.59, and $44(11.73 \%)$ a GPA $<3.09$. Table 2 shows the most important factors influencing the choice of a future specialty among all participants. Lifestyle was chosen by 168 (44.7\%) participants as the most influential factor for their choice of a future specialty, followed by subspecialty choices in $49(13 \%)$ participants and clinical rotation experience in $43(11.4 \%)$ participants. Medical interns considered lifestyle as an important factor compared with medical students and it was found statistically significant $(P=0.020)$. Internal medicine was the preferred specialty for 56 participants (14.77\%), followed by family medicine for 35 participants (9.2\%). Thirty-four participants $(8.97 \%)$ chose general surgery, and 27 participants $(7.1 \%)$ chose both pediatrics and emergency medicine. Sex influences indicated that men preferred pediatrics and emergency medicine $(P=0.033$ and $P=0.0006$, respectively), while women preferred family medicine practice $(P=0.034)$.

Logistic regression analysis showed that sex was the only independent factor to significantly influence participants' motivation for their choice as a dependent factor (Table 5). 
Table 5 Dependent variable: motivational factor

\begin{tabular}{lllllll}
\hline Model & \multicolumn{2}{l}{$\begin{array}{l}\text { Nonstandardized } \\
\text { coefficients }\end{array}$} & & $\begin{array}{l}\text { Standardized } \\
\text { coefficients }\end{array}$ & $T$ & P-value \\
\cline { 2 - 3 } & Beta & $\begin{array}{l}\text { Standard } \\
\text { error }\end{array}$ & Beta & & \\
\hline Constant & 3.008 & 1.197 & & 2.513 & 0.012 \\
Age & -0.573 & 0.530 & & -0.063 & -1.081 & 0.280 \\
Sex & 1.060 & 0.420 & & 0.150 & 2.523 & 0.012 \\
Level & -0.172 & 0.200 & & -0.053 & -0.859 & 0.391 \\
GPA & -0.023 & 0.161 & & -0.008 & -0.144 & 0.885 \\
\hline
\end{tabular}

Abbreviation: GPA, grade point average.

\section{Discussion}

Our study showed that Saudi medical students and interns in the Eastern region defined lifestyle (controllable versus uncontrollable) as the most influential and important factor while choosing a specialty for their future medical career. We found that our students were not so different from those in other parts of the world. For example, Lefevre et $\mathrm{al}^{5}$ found that lifestyle is the main reason why French students avoid certain medical specialties. Newton et $\mathrm{al}^{6}$ studied 1,327 graduates from two different US medical schools (New York Medical College and the Brody School of Medicine at East Carolina University), who indicated that lifestyle and income were the two factors that influenced their career choice. Future Canadian doctors indicated that as many as five factors influenced their medical specialty preferences, which were lifestyle, societal orientation, prestige, hospital orientation, and varied scope of practice. ${ }^{7}$ The question of controllable lifestyle was discussed in a US study that examined the influence of controllable lifestyle on the choice of a specialty, but no trend was found between the choices and the sex of the participants. ${ }^{1}$

Two other factors that our study group considered important were subspecialty choices followed by clinical rotation experience, where the former reflects the aspirations that new graduates consider when thinking about their future career. Clinical rotation experience was found in some studies to have a positive influence on the future specialty choice. Studies have shown that their first clinical rotation experience affects male medical students' specialty preference and that their clerkship experience plays a major role in the specialty choice of internal medicine. ${ }^{8,9}$

In this study, the first choice of all participants was the specialty of internal medicine. There was no statistical difference between the sexes and education level of the participants (Figure 1). Factors that influence medical students to choose the specialty of internal medicine have been studied elsewhere; educational experiences, lifestyle, and the nature of patient care in internal medicine practice were the main reasons for choosing that specialty. ${ }^{10}$ The second choice for female participants was family medicine. Family medicine practice in Saudi Arabia is attractive to females as the working hours are less, and this is explained by the fact that family physicians are underutilized by the general public in Saudi Arabia, which is reflected by a large number of unnecessary emergency department visits of less urgent cases, which could be avoided if a specialized family physician was available for visits regularly. This is not the case in North America, where family practice has long clinical hours and a heavy workload with different public awareness and utilization.

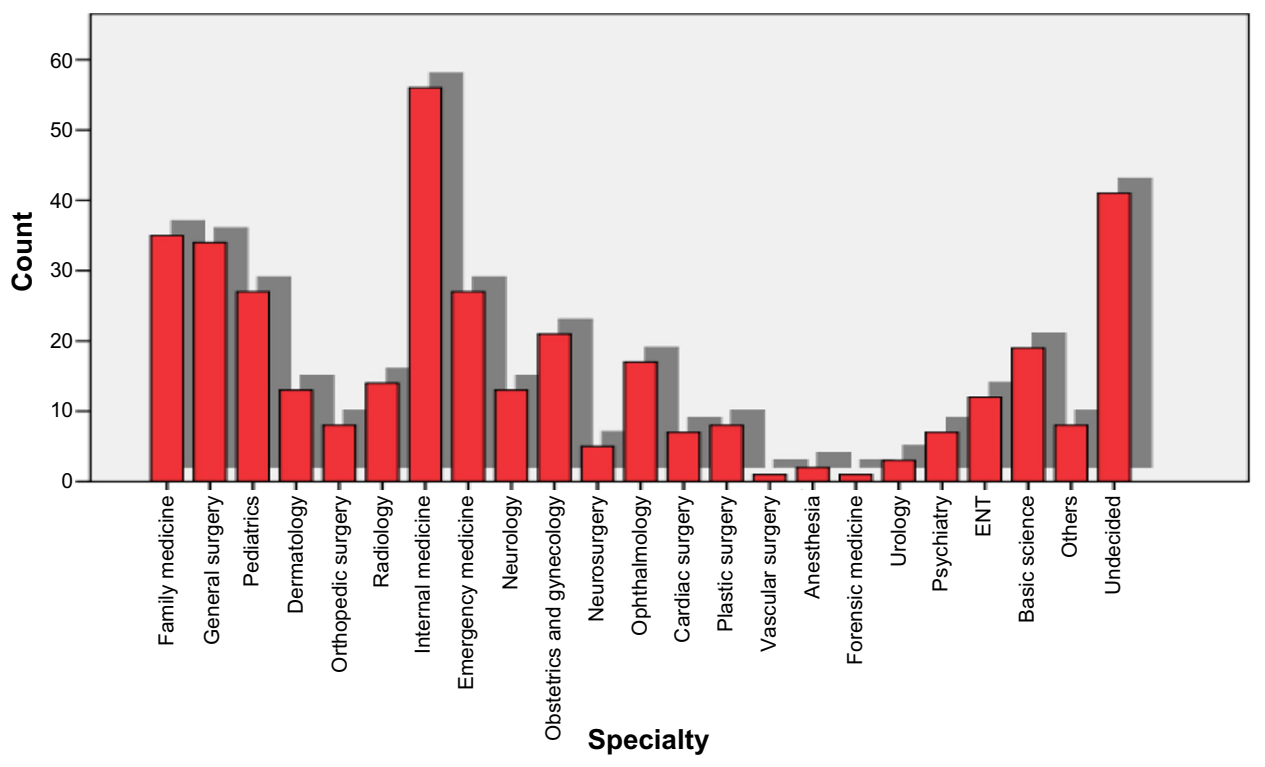

Figure I Distribution of specialty preferences among participants. Note: ENT, ear, nose, and throat. 
In their study, Senf et $\mathrm{al}^{11}$ found income expectations, prestige, and the required breadth of knowledge were the most influential factors that attract students to family medicine. In our cohort, we found that males opted for emergency medicine, which is more challenging (Table 3 ). Sex differences have been investigated at a national level. At Taibah University, Zolaly et al ${ }^{12}$ found that marital status plays a major role among females when they consider their future specialty, while personality and work achievement play a major role among males. In their study, Eze et al ${ }^{13}$ found that factors such as personal interest, career prospects, and personal skills/aptitude influenced medical students in their choice of a medical specialty. The top choices were surgery and pediatrics. Similarly, Al-Fouzan et al ${ }^{14}$ found pediatrics, general surgery, and cardiology were the most liked specialties because their participants thought they were challenging, but with good patient treatment outcomes.

Another important question addressed was where the participants would like to continue their further training. There was no statistically significant difference between the participants' choice of training in Saudi Arabia when compared with USA and Canada (Table 4). To the best of our knowledge, the question of preference of training location has not been addressed at the national level. The answers would be useful to anticipate future demand for places locally and internationally. This would affect hiring staff in all local institutes, and strategies to implement international scholarships versus local ones could be needed.

By knowing students' interest for specialty selection, the future trend of students regarding specialty choice can be predicted. This might raise the need for specialists in the most demanding specialties. More than $50 \%$ of the students were interested in selecting the first six specialties out of 24 listed in Table 1. From the students' responses, it seems that in the future there will be more specialists in the fields of internal medicine, general surgery, pediatrics, obstetrics and gynecology, emergency medicine, and family medicine. But there are many other fields for specialization, so there is a need to make students aware of them and to create interest in them, so that the Eastern region and Saudi Arabia will have specialties in every medical field.

The findings of the study also have other important implications for medical education in Saudi Arabia. The findings indicate the possible future availability of appropriately trained specialists in a wide range of the medical specialties where most of them will be future educators in residency training programs. Locally, this will minimize the future need for scholarships abroad, with their overall disadvantage of acceptance time delay and costs. Having enough specialists in most of the specialties will reinforce all aspects of research, which is considered to be in its infancy in our area. In conjunction with other national studies in the western and southern regions by Zolaly et $\mathrm{al}^{12}$ and Mehmood et al, ${ }^{4}$ respectively, we might be able to achieve more generalizable knowledge about factors that influence Saudi medical students in their future career choice.

Our study has one limitation. Our small number of participants does not allow any definite conclusions because only half of the intended participants replied to our questionnaire.

\section{Conclusion}

This study shows that Saudi medical students and interns make their choice of specialist training early (before graduation). Medical school administrators can act on this to effectively manage future staffing needs in various specialty fields. Participants indicated that maintaining their lifestyle in their future career was the most influential factor in choosing a specialty. The majority of participants (male and female) preferred internal medicine. Family practice, with its shorter working day, was a close second choice for females.

\section{Acknowledgment}

The authors would like to thank M Sadat Ali.

\section{Disclosure}

The authors report no conflicts of interest in this work.

\section{References}

1. Dorsey ER, Jarjoura D, Rutecki GW. Influence of controllable lifestyle on recent trends in specialty choice by US medical students. JAMA. 2003;290(9):1173-1178.

2. Telmesani A, Zaini RG, Ghazi HO. Medical education in Saudi Arabia: a review of recent developments and future challenges. East Mediterr Health J. 2011;17(8):703-707.

3. Ministry of Health, Kingdom of Saudi Arabia: Statistics Book; 2014. Available from: http://www.moh.gov.sa/en/Ministry/Statistics/Book/ Pages/default.aspx. Accessed Dec 2013.

4. Mehmood SI, Kumar A, Al-Binali A, Borleffs JC. Specialty preferences: trends and perceptions among Saudi undergraduate medical students. Med Teach. 2012;34(Suppl 1):S51-S60.

5. Lefevre JH, Roupret M, Kerneis S, Karila L. Career choices of medical students: a national survey of 1780 students. Med Educ. 2010;44(6): 603-612.

6. Newton DA, Grayson MS, Thompson LF. The variable influence of lifestyle and income on medical students' career specialty choices: data from two US medical schools, 1998-2004. Acad Med. 2005;80(9): 809-814

7. Wright B, Scott I, Woloschuk W, Brenneis F, Bradley J. Career choice of new medical students at three Canadian universities: family medicine versus specialty medicine. CMAJ. 2004;170(13):1920-1924. 
8. Coffeng LE, Visscher AJ, Ten Cate OT. The influence of early clinical experiences on career preference of male and female medical students. Med Teach. 2009;31(7):e323-e326.

9. Ellsbury KE, Carline JD, Irby DM, Stritter FT. Influence of third-year clerkships on medical student specialty preferences. Adv Health Sci Educ Theory Pract. 1998;3(3):177-186.

10. Hauer KE, Durning SJ, Kernan WN, et al. Factors associated with medical students' career choices regarding internal medicine. JAMA. 2008;300(10):1154-1164.

11. Senf JH, Campos-Outcalt D, Kutob R. Factors related to the choice of family medicine: a reassessment and literature review. J Am Board Fam Pract. 2003;16(6):502-512.
12. Zolaly MA, Kasim K, Mahmoud MI. Medical career selection among newly graduated physicians in Madinah, KSA. Med Teach. 2013;35(Suppl 1):S63-S67.

13. Eze BI, Okoye OI, Maduka-Okafor FC, Aguwa EN. Factors influencing choice of medical specialty of preresidency medical graduates in southeastern Nigeria. J Grad Med Educ. 2011;3(3): 367-371.

14. Al-Fouzan R, Al-Ajlan S, Marwan Y, Al-Saleh M. Factors affecting future specialty choice among medical students in Kuwait. Med Educ Online. 2012;17:1-7.

\section{Publish your work in this journal}

Advances in Medical Education and Practice is an international, peerreviewed, open access journal that aims to present and publish research on Medical Education covering medical, dental, nursing and allied health care professional education. The journal covers undergraduate education, postgraduate training and continuing medical education including emerging trends and innovative models linking education, research, and health care services. The manuscript management system is completely online and includes a very quick and fair peer-review system. Visit http://www.dovepress.com/testimonials.php to read rea quotes from published authors.

Submit your manuscript here: http://www.dovepress.com/advances-in-medical-education-and-practice-journal 